The University of Southern Mississippi

The Aquila Digital Community

Faculty Publications

$4-1-2014$

\title{
Health Insurance Status, Psychological Processes, and Older African Americans' Use of Preventive Care
}

\author{
Catherine Walker O'Neal \\ University of Georgia, cwalker1@uga.edu \\ Kandauda A.S. Wickrama \\ University of Georgia, wickrama@uga.edu \\ Penny A. Ralston \\ Florida State University, pralston@fsu.edu \\ Jasminka Z. Elich \\ Florida State University, jilichernst@fsu.edu \\ Cynthia M. Harris \\ Florida A\&M University, Cynthia.harris2@famu.edu
}

See next page for additional authors

Follow this and additional works at: https://aquila.usm.edu/fac_pubs

Part of the Nutrition Commons

\section{Recommended Citation}

O'Neal, C. W., Wickrama, K. A., Ralston, P. A., Elich, J. Z., Harris, C. M., Coccia, C., Young-Clark, I., Lemacks, J. (2014). Health Insurance Status, Psychological Processes, and Older African Americans' Use of Preventive Care. Journal of Health Psychology, 19(4), 491-502.

Available at: https://aquila.usm.edu/fac_pubs/8058

This Article is brought to you for free and open access by The Aquila Digital Community. It has been accepted for inclusion in Faculty Publications by an authorized administrator of The Aquila Digital Community. For more information, please contact Joshua.Cromwell@usm.edu. 


\section{Authors}

Catherine Walker O'Neal, Kandauda A.S. Wickrama, Penny A. Ralston, Jasminka Z. Elich, Cynthia M. Harris, Catherine Coccia, Iris Young-Clark, and Jennifer Lemacks 


\title{
Health insurance status, psychological processes, and older African Americans' use of preventive care
}

\author{
Catherine W O'Neal ${ }^{1}$, K. A. S Wickrama ${ }^{1}$, Penny A Ralston ${ }^{2}$, Jasminka Z Ilich ${ }^{2}$, Cynthia M \\ Harris $^{3}$, Catherine Coccia ${ }^{4}$, Iris Young-Clark ${ }^{2}$, and Jennifer Lemacks ${ }^{5}$ \\ ${ }^{1}$ University of Georgia, USA \\ ${ }^{2}$ Florida State University, USA \\ ${ }^{3}$ Florida A\&M University, USA \\ ${ }^{4}$ Texas A\&M University-Kingsville, USA \\ ${ }^{5}$ University of Southern Mississippi, USA
}

\begin{abstract}
The current study examined the influence of health insurance, psychological processes (i.e. psychological competency and vulnerability), and the interaction of these two constructs on older African Americans' utilization of five preventive care services (e.g. cholesterol screening and mammogram/prostate examination) using data from 211 older African Americans (median age $=$ 60). In addition to direct effects, the influence of health insurance sometimes varied depending on respondents' psychological competency and/or vulnerability. Policies and interventions to increase older African Americans' use of preventive health services should consider structural (e.g. health insurance) and psychological (e.g. psychological competency and vulnerability) factors along with the interaction between these factors.
\end{abstract}

\section{Keywords}

African Americans; control; health insurance; preventive care; vulnerability

\begin{abstract}
The behavioral model of health services use was developed to further the understanding of factors that determine families' use of health services (Andersen, 1968). The principle tenets of the behavioral model of health services use include that both individuals' predisposing psychological characteristics and available structural resources, such as health insurance, influence the use of health-care services (Andersen, 1995). Furthermore, both quantitative and qualitative studies have emphasized the influence of social-psychological and structural barriers to individuals' receipt of adequate health care and, more broadly, their overall health (Lavelle et al., 2012; Ratna and Rifkin, 2007). However, little consideration has been given to how psychological and structural characteristics may interact to explain why certain individuals are more likely to access health care. Thus, in the present study, in addition to the direct additive influence of health insurance and predisposing psychological characteristics, we examine whether psychological characteristics combine with health insurance status to influence (i.e. encourage or hinder) the use of preventive care services in a sample of older African Americans.
\end{abstract}

\footnotetext{
(C) The Author(s) 2013
}

Corresponding author: Catherine W O'Neal, Department of Child and Family Development, 107 Family Science Center II, 405 Sanford Drive, The University of Georgia, Athens, GA 30602, USA. cwalker1@uga.edu. 
This area of research is particularly relevant and important for African Americans for several reasons. They are disproportionally positioned in the lower levels of the socioeconomic status (SES) hierarchy, which increases their risk of encountering structural barriers to not having health insurance. Furthermore, preventive care may be highly beneficial for African Americans because national data show that African Americans experience high age-adjusted morbidity and mortality rates and high prevalence rates of many diseases (e.g. chronic health conditions such as hypertension and diabetes) and health risk behaviors (e.g. fat consumption) (House et al., 2005; Warner and Hayward, 2006). However, African Americans, on average, utilize fewer preventive health services than other ethnicities (Bennett et al., 2009). Finally, research has noted that social-psychological and behavioral processes may differ across various racial or ethnic groups (Goodwin, 2003). Because there are intragroup variations in African Americans' psychological characteristics, health insurance procurement, and preventive care use, we expect to examine the unique processes involving these constructs within this population.

\section{The role of psychological characteristics}

Based on existing research (Seligman and Csikszentmihalyi, 2000; Wickrama et al., 2012a), we conceptualize that psychological competency, reflected by one's positive feelings about one's abilities, and psychological vulnerability, reflected by negative and depressed feelings, are two distinct constructs rather than opposite ends of the same construct. This conceptualization is supported by research that has shown that psychological competency and vulnerability have different health consequences and unique antecedents (Kobau et al., 2011; Noh et al., 2007; Wickrama et al., 2012a). For example, Wickrama et al. (2012c) have shown that stressful economic circumstances directly contribute to individuals' negative depressed feelings and at the same time erode his or her positive feelings of self.

\section{Psychological competency}

Drawing from Andersen's (1995) behavioral model of health services use, psychological competency may directly promote the utilization of preventive health services. Individuals with positive feelings are more likely to recognize the importance of health-promoting behaviors and believe that they can personally take actions to maintain and/or improve their health (Ajzen, 2002; Thompson, 1981). Furthermore, psychological competency is associated with one's empowerment and motivation, which is essential for building individuals' capacity to engage in health-promoting behaviors (Aoun et al., 2009; Berg et al., 2008; Ratna and Rifkin, 2007). We contend that psychological competency is a broad construct of positive feelings with various dimensions. Accordingly, previous researchers have defined and used numerous closely related psychological constructs, such as sense of control (Mirowsky and Ross, 1991), mastery (Pearlin et al., 1981), hardiness (Kobosa, 1979), self-efficacy (Bandura, 1992), and sense of coherence (Antonovsky, 1979), to capture different dimensions of one's psychological competency or positive feelings. These constructs have also been used as multiple indicators to define a latent construct that is similar to our construct of psychological competency (e.g. O'Neal et al., 2012; Whitbeck et al., 1997).

Numerous studies assessing these more specific dimensions of psychological competency (e.g. self-efficacy and sense of control) have demonstrated their positive influence on a variety of health-promoting behaviors, such as diet, exercise, oral hygiene, and receiving preventive health care (Buglar et al., 2010; Menec and Chipperfield, 1997; Richert et al., 2010, Seeman and Seeman, 1983; Woodgate and Brawlay, 2008). Thus, consistent with the behavioral model of health services use (Andersen, 1995), we hypothesize that within our sample of African Americans, psychological competency will positively influence their use of preventive care. 


\section{Psychological vulnerability}

Following Andersen's (1995) behavioral model of health services use, whereas psychological competency likely promotes health-enhancing behaviors, negative predisposing characteristics, such as an individual's depressed feelings (hereafter referred to as psychological vulnerability), may discourage participation in health-enhancing behaviors. This association is also supported by existing research noting that distressed feelings can make performing even basic tasks difficult and may leave an individual with little time or energy to perform health-enhancing behaviors, such as physical activity and scheduling/ attending preventive care appointments (Pratt and Brody, 2008). For instance, distressed older African Americans report less exercise and a less healthy nutritional status compared to older African Americans with a lower level of depressive symptoms (Patil et al., 2008). Similarly, a study of older women found that depressive symptoms reduced the likelihood of several preventive care behaviors including receiving an influenza vaccination, cholesterol screening, mammogram, and Pap smear test (Baker and Silverstein, 2008). Thus, consistent with the behavioral model of health services use (Andersen, 1995), we hypothesize that within our sample of African Americans, psychological vulnerability will negatively influence their use of preventive care.

\section{Health insurance status and preventive health care}

In addition to characteristics of the individual, Andersen's (1995) behavioral model of health services use posits that structural resources, including the availability of health insurance, also directly influence the likelihood that an individual will utilize health services. The benefits of health insurance have been examined and widely acknowledged in existing research. Studies have identified lack of health insurance as the primary barrier to preventive health care (Anderson et al., 2010; Currie et al., 2008; Kiyak and Reichmuth, 2005; Malmgren et al., 1996). Consequently, insurance status has been shown to increase contact with a physician, doctor visits, and the likelihood of having a routine physical and dental checkup (Manski et al., 2004; Wolinsky and Johnson, 1991). Thus, consistent with the behavioral model of health services use (Andersen, 1995), we hypothesize that African Americans with health insurance will be more likely to utilize preventive health care than those without health insurance.

\section{Interaction with psychological processes}

In addition to the direct effects of psychological processes (i.e. psychological competency and vulnerability) and health insurance on utilizing preventive care, these constructs may interact with each other to explain additional variation in the use of preventive care services. For instance, individuals' evaluation of resources and costs have been shown to interact with their self-efficacy, a psychological process linked to psychological competency, to influence health behaviors such as acquiring knowledge of health issues and utilizing this information (Rimal, 2001). However, to our knowledge, the interactive effect between health insurance and psychological processes in explaining preventive care use has not been examined within existing research. Individuals with low levels of psychological competency or high levels of psychological vulnerability may be more dependent on the availability of health insurance for preventive care uses. Therefore, we hypothesize that these psychological processes may interact with health insurance status to explain the extent of preventive care used by older African Americans. 


\section{Methods}

\section{Sample}

Baseline data from participants of six churches participating in a National Institutes of Health (NIH)-funded project to reduce cardiovascular risk in midlife and older African Americans (Ralston, Ilich-Ernst, Wickrama, \& Harris, 2008) in North Florida were used for the current study. Respondents were 211 older African American women and men (73\% female and $26 \%$ male) with a median age of 60 years. Having a "high school diploma" $(31.6 \%)$ and attended "some college" (30.6\%) were the most common educational levels. On average, respondents were married (45.5\%) with two children $(29.8 \%)$. The percentage of missing responses per variable ranged from 0.5 to 4.3 percent with a mean missing percentage of 1.95. Full information maximum likelihood (FIML), which provides more efficient parameter estimates compared to other procedures for handling missing data, was used to estimate missing data (Enders, 2001).

\section{Measures}

Outcome variables: Use of preventive health services-Respondents indicated how often they utilized six common preventive health services. Services included receiving a physical examination at a doctor's office, having blood pressure taken by the doctor, having a blood test for diabetes, having cholesterol taken by the doctor, and having a gender-specific cancer screening (i.e. mammogram or prostate examination). Response categories included "never" (1), "occasionally" (2), and "regularly" (3). Each health service was analyzed as a separate outcome variable in order to assess how the utilization of health services is differentially influenced by the variables of interest in the current study.

Health insurance status-A single dichotomous item assessed whether respondents currently had health insurance $(1=$ no; $2=$ yes $)$.

Psychological processes-Although the Perceived Stress Scale (PSS; Cohen et al., 1983) is generally used as a single measure of perceptions of stress, a confirmatory factor analysis (CFA) revealed two distinct factors within this scale of 12 items (Figure 1; adapted from Wickrama et al., 2012b). These two factors reflect respondents' psychological competency and vulnerability to stress. The correlation between these two factors was not statistically significant $(r=-.10, p=.22)$ showing good discriminant validity. This was also supported by the nonsignificant bivariate correlation between psychological competency and vulnerability in the current study $(r=.13, p=\mathrm{ns})$, which confirms the discriminant validity of these constructs.

Psychological competency-Positive feelings and thoughts about life circumstances (i.e. psychological competency) in the last month were assessed using five items from the PSS (Cohen et al., 1983). Item responses range from "never" (0) to "very often" (4). Sum scores were computed with higher scores indicating greater psychological competency. Questions included "How often have you felt that you were effectively coping with important changes that were occurring in your life?"; "How often have you felt confident about your ability to handle your personal problems?"; "How often have you felt things were going your way?"; "How often have you been able to control the irritations in your life?"; and "How often have you been able to control the way you spend your time?" The scale had adequate internal consistency $(a=0.80)$.

Psychological vulnerability-Depressed feelings (i.e. psychological vulnerability) in the last month were assessed using seven items from the PSS (Cohen et al., 1983). Response categories ranged from "never" (0) to "very often" (4). Sum scores were computed with 
higher scores indicating greater psychological vulnerability. Questions included "How often have you been upset because of something that happened unexpectedly?"; "How often have you felt that you were unable to control the important things in your life?"; "How often have you felt nervous and stressed?"; "How often have you found that you could not cope with all the things that you had to do?"; "How often have you been angered because of things that happened outside of your control?"; "How often have you found yourself thinking about things that you have to accomplish?"; and "How often have you felt difficulties were piling up so high that you could not overcome them?" The scale had adequate internal consistency $(a=0.85)$.

Control variables-Age, gender, marital status, education, and health status were included as control variables in the current analyses. Age was assessed using 12 categories ranging from "18-21" to "over 91." Gender was coded as "female" (1) and "male" (2). Marital status was coded dichotomously as "married" (1) or "not married" (0). Respondents provided their education level using eight categories ranging from "some high school" (1) to a "law degree" (8). They rated their health status from "poor" (1) to "excellent" (5).

\section{Analyses}

Structural equation modeling (SEM) with Amos 17.0 (Arbuckle, 2006) was used to determine whether older African Americans' use of preventive health services varies according to their health insurance status. The interactive effect of psychological processes and health insurance status on the utilization of health services was examined using centered product terms to determine whether the association between health insurance status and the use of health services differed depending on older African Americans' psychological competency and vulnerability. Goodness-of-fit was assessed using the chi-square statistic, comparative fit index (CFI), and root mean square error of approximation (RMSEA).

\section{Results}

Descriptive statistics and bivariate zero-order correlations among all study variables are shown in Table 1. Eleven percent of respondents reported that they did not currently have health insurance. This is slightly lower than the national average of 16.0 percent (Cohen et al., 2011). The discrepancy may be due to the older age of our sample as many of the respondents may have qualified for public coverage (e.g. Medicare) available to older adults. On average, respondents reported feelings of psychological competency "fairly often" ( $M=$ $15.94, S D=4.34)$ and psychological vulnerability occasionally $(M=12.69, S D=5.48)$. Overall, respondents reported having each of the preventive health screenings fairly regularly. Most respondents reported that their health was fair to good $(M=3.57, S D=$ 0.77).

Overall, individuals who reported receiving regular health services for one screening also reported receiving other health screenings regularly. However, receiving mammograms and prostate examinations were not significantly associated with having blood pressure $(r=.05)$, diabetes, $(r=.13)$, or cholesterol $(r=.09)$ screenings.

Two structural equation models examining health insurance status, psychological processes, and preventive health services use after controlling for education, age, marital status, sex, and perceived general health status were conducted in order to assess the moderating role of psychological processes (i.e. psychological competency and vulnerability) separately. Figure 2 displays statistically significant paths from the model examining the influence of health insurance and psychological competency on older African Americans' use of five preventive health services after taking the covariance among the outcome variables into account. Older African Americans' health insurance status was positively associated with four of the health 
services, including regularly receiving physical checkups $(\beta=0.33, p<.01)$, having a doctor measure blood pressure $(\beta=0.19, p<.01)$, receiving diabetes screenings $(\beta=0.24, p<.01)$, and receiving cholesterol screenings $(\beta=0.26, p<.01)$. Psychological competency promoted frequent physical checkups $(\beta=1.40, p<.01)$ and cholesterol screenings ( $\beta=$ $1.36, p<.01)$. Older African American males $(\beta=0.22, p<.01)$ and those with perceived poor health $(\beta=-0.20, \mathrm{p}<.01)$ were more likely than females and those who perceived themselves as healthy to have regular gender-specific cancer screenings.

The psychological competency and insurance status product term was statistically significant for two of the health services, physical checkups and cholesterol screenings ( $\beta=$ $-1.36, p<.01$ and $\beta=-1.34, p<.01$, respectively), and marginally significant for blood pressure screenings ( $\beta=-0.78, p=.06$ ). This indicates that the influence of health insurance status on these preventive health services was stronger for those with low levels of psychological competency. Thus, the effectiveness of health insurance for increasing individuals' health-promoting behaviors is greater for those with lower psychological competency than individuals with higher psychological competency. Use of the preventive health services was significantly correlated with each other ( $r$ ranged from .28 to .65$)$ with the exception of mammogram/prostate examination, which was not correlated with any of the four other health services. Overall, this model fit the data reasonably well (CFI $=.97$, RMSEA $=.07$, and $\left.\chi^{2} / \mathrm{df}(32)=2.03\right)$.

Figure 3 displays statistically significant paths from the model examining the influence of health insurance and psychological vulnerability on older African Americans' use of five preventive health services after taking the covariances among the outcome variables into account. Having health insurance was associated with regularly receiving physical checkups ( $\beta=0.31, p<.01)$, having a doctor measure blood pressure $(\beta=0.17, p<.05)$, receiving diabetes screenings $(\beta=0.15, p<.05)$, and receiving mammograms or prostate examinations $(\beta=0.19, p<.01)$. Psychological vulnerability inhibited frequent diabetes and cholesterol screenings $(\beta=-1.54, p<.01$ and $\beta=-1.09, p<.01$, respectively). Older African American males $(\beta=0.20, p<.01)$ and married individuals $(\beta=0.13, p<.05)$ were more likely than females and healthy individuals to have regular gender-specific cancer screenings. Yet married individuals were less likely to have a doctor test their blood pressure frequently $(\beta=-0.12, p<.01)$.

The psychological vulnerability and insurance status product term was statistically significant for three of the health services: diabetes screenings $(\beta=1.40, p<.01)$, and cholesterol screenings $(\beta=0.98, p<.01)$, and gender-specific cancer screenings $(\beta=0.69, p$ $<.05$ ), which indicates that the influence of health insurance status on older African Americans' use of these preventive health services was greater for individuals with a high level of psychological vulnerability than those with a low level of psychological vulnerability. Use of the preventive health services was significantly correlated with the other health services ( $r$ range from .27 to .66) with the exception of mammogram/prostate examination, which was not correlated with any of the four other health services. Overall, this model fit the data reasonably well $\left(\mathrm{CFI}=.97, \mathrm{RMSEA}=.07\right.$, and $\left.\chi^{2} / \mathrm{df}(26)=2.27\right)$.

\section{Discussion}

Overall, these findings indicate that two psychological processes (competency and vulnerability) and health insurance are directly associated with older African Americans' use of several preventive health screenings. The results indicate that, for those with low psychological competency and high psychological vulnerability, having health insurance increased the likelihood of receiving regular preventive care. 
These results were consistent with the behavioral model of health services use (Andersen, 1995) and past findings (Baker and Silverstein, 2008; Manski et al., 2004; Menec and Chipperfield, 1997; Seeman and Seeman, 1983; Wolinsky and Johnson, 1991). Older African Americans have likely encountered cumulative stressful life experiences, such as day-to-day discrimination and economic hardship (Shuey and Wilson, 2008; Taylor and Turner, 2002), that are reflected in their feelings and thoughts about life circumstances/ events (i.e. psychological competency and vulnerability) in their older years. Thus, the current findings of direct additive effects involving these psychological processes may be another example of the harmful influence of chronic stress on health-promoting behaviors of older African Americans (Wickrama et al., 2012b).

However, these results show that older African Americans with high levels of psychological competency and low levels of psychological vulnerability generally report a high level of preventive care utilization regardless of their health insurance status. Thus, health insurance is important for the utilization of preventive care for distressed older African Americans, although health insurance has little impact on the use of preventive care for older African Americans not experiencing psychological distress. It should be noted that utilization of preventive care screenings was extremely high for those with high levels of psychological competency and low levels of psychological vulnerability regardless of their health insurance status. Thus, this ceiling effect made it impossible for scores to increase further. Using a more sensitive measure of preventive care, researchers may also detect variation in behavior for those with health insurance across levels of psychological competency and vulnerability.

Of the five demographic characteristics (age, gender, marital status, education, and perceived health status) we took included in our analyses only a few demographics were associated with preventive care use. Interestingly, all the significant paths involving demographic characteristics pertained to receiving gender-specific cancer screenings. Furthermore, this was the one preventive care behavior not influenced by health insurance or psychological processes, which suggests that the preventive care behaviors we examined are distinctive, particularly gender-specific cancer screenings, with unique predictors of each.

Several limitations must be taken into consideration regarding the current study and its findings. First, our reliance on a dichotomous yes/no response indicating participants' health insurance status is, perhaps, the most confining limitation. Based on this information, we are unable to determine whether the utilization of preventive care varies across insurance type or quality. Second, studies replicating these findings with more generalizable samples would be informative for determining whether these processes occur similarly for other ethnicities and age groups. Furthermore, our sample included African American churchgoers participating in a larger intervention project. Thus, it is unclear how findings from this sample generalize to other religious groupings or nonreligious groupings. Third, the cross-sectional nature of this analysis limits our ability to account for the duration of participants' health insurance.

Policies and programs addressing the health behaviors of older African Americans are particularly important due to the high age-adjusted morbidity and mortality rates of African Americans (National Center for Health Statistics, 2006), and currently, the provision of health insurance is a major goal of policies addressing health care and health outcomes. Policies and interventions aiming to improve older African Americans' health outcomes by increasing their use of preventive health services should consider structural (e.g. health insurance status) and psychological (e.g. psychological competency and vulnerability) factors as well as the interaction between these factors, simultaneously. 


\section{Acknowledgments}

\section{Funding}

The project described was supported by Award Number R24MD002807 (Penny A. Ralston, Principal Investigator) from the National Institute on Minority Health and Health Disparities. The content is solely the responsibility of the authors and does not necessarily represent the official views of the National Institute on Minority Health and Health Disparities or the National Institutes of Health.

\section{References}

Ajzen I. Perceived behavioral control, self-efficacy, locus of control, and the theory of planned behavior. Journal of Applied Social Psychology. 2002; 32:665-683.

Andersen, RM. Behavioral Model of Families' Use of Health Services. Chicago, IL: Center for Health Administration Studies, University of Chicago; 1968. Research Series, 25

Andersen RM. Revisiting the behavioral model and access to medical care: Does it matter? Journal of Health and Social behavior. 1995; 36:1-10. [PubMed: 7738325]

Anderson, M.; Dobkin, C.; Gross, T. The effects of health insurance coverage on the use of medical services. National Bureau of Economic Research Working Paper No. 15823; 2010. March 2010; http://www.nber.org/papers/w15823

Antonovsky, A. Health, Stress and Coping. San Francisco, CA: Jossey-Bass; 1979.

Aoun S, Osseiran-Moisson F, Collins R, et al. A self-management concept for men at the community level: The "waist" disposal challenge. Journal of Health Psychology. 2009; 14:663-674. [PubMed: 19515681]

Arbuckle, JL. Amos (Version 7.0). Chicago, IL: SPSS; 2006. Computer Program

Baker LA, Silverstein M. Preventive health behaviors among grandmothers raising grandchildren. The Journals of Gerontology Series B, Psychological Sciences and Social Sciences. 2008; 63:S304S311.

Bandura, A. Exercise of personal agency through the self-efficacy mechanism. In: Schwarzer, R., editor. Self-Efficacy: Thought Control of Action. Washington, DC: Hemisphere Publishing Corporation; 1992. p. 3-38.

Bennett IM, Chen J, Soroui JS, et al. The contribution of health literature to disparities in self-rated health status and preventive health behaviors in older adults. Annals of Family Medicine. 2009; 7:204-211. [PubMed: 19433837]

Berg CJ, Cox LS, Mahnken JD, et al. Correlates of self-efficacy among rural smokers. Journal of Health Psychology. 2008; 13:416-421. [PubMed: 18420774]

Buglar M, White KM, Robinson NG. The role of self-efficacy in dental patients' brushing and flossing: Testing an extended health belief model. Parent Education and Counseling. 2010; 78:269-272.

Cohen, RA.; Ward, BW.; Schiller, JS. Health insurance coverage: Early release estimates from the national health interview survey, 2010. Centers for Disease Control and Prevention; 2011. June 2011; http://www.cdc.gov/nchs/data/nhis/earlyrelease/insur201106.pdf

Cohen S, Kamarck T, Mermelstein R. A global measure of perceived stress. Journal of Health and Social behavior. 1983; 24:385-396. [PubMed: 6668417]

Currie J, Decker S, Lin W. Has public health insurance for older children reduced disparities in access to care and health outcomes? Journal of Health Economics. 2008; 27:1567-1581. [PubMed: 18707781]

Enders CK. The performance of the full information maximum likelihood estimation in multiple regression models with missing data. Educational and Psychological Measurement. 2001; 61:713740.

Goodwin PY. African American and European American women's marital well-being. Journal of Marriage and the Family. 2003; 65:550-560.

House JS, Lantz PM, Herd P. Continuity and change in the social stratification of aging and health over the life course: Evidence from a nationally representative longitudinal study from 1986 to 
2001/2002 (Americans' changing lives study). The Journals of Gerontology. Series B, Psychological Sciences and Social Sciences. 2005; 60(Special Issue II):15-26.

Kiyak HA, Reichmuth M. Barriers to and enablers of older adults' use of dental services. Journal of Dental Education. 2005; 69:975-986. [PubMed: 16141083]

Kobau R, Seligman MEP, Peterson C, et al. Mental health promotion in public health: Perspectives and strategies from positive psychology. American Journal of Public Health. 2011; 101:e1-e9. [PubMed: 21680918]

Kobosa S. Stressful life events, personality, and health: An inquiry into hardiness. Journal of Personality and Social Psychology. 1979; 37:1-11. [PubMed: 458548]

Lavelle B, Lorenz FO, Wickrama KAS. What explains divorced women's poorer health? The mediating role of health insurance and access to health care in a rural Iowan sample. Rural Sociology. 2012; 77:601-625. [PubMed: 23457418]

Malmgren JA, Martin ML, Nicola RM. Health care access of poverty-level older adults in subsidized public housing. Public Health Reports. 1996; 111:260-263. [PubMed: 8643819]

Manski RJ, Goodman HS, Reid BC, et al. Dental insurance visits and expenditures among older adults. American Journal of Public Health. 2004; 94:759-764. [PubMed: 15117697]

Menec VH, Chipperfield JG. Remaining active in later life: The role of locus of control in seniors' leisure activity participation, health, and life satisfaction. Journal of Aging and Health. 1997; 9:105-125. [PubMed: 10182413]

Mirowsky J, Ross CE. Eliminating defense and agreement bias fro measures of sense of control. Social Psychology Quarterly. 1991; 55:217-235.

National Center for Health Statistics (US). Health, United States, 2006; With Chartbook on Trends in the Health of Americans. Hyattsville (MD): National Center for Health Statistics (US); 2006 Nov. Available fromhttp://www .ncbi.nlm.nih.gov/books/NBK21002/

Noh S, Kaspar V, Wickrama KAS. Overt and subtle racial discrimination and mental health: Preliminary findings for Korean immigrants. American Journal of Public Health. 2007; 97:12691274. [PubMed: 17538066]

O'Neal CW, Wickrama KAS, Bryant CM. Control over work, positive self, and health among African American husbands and wives. Journal of Family Issues. 2012

Patil SK, Johnson AS, Lichtenberg PA. The relation of pain and depression with various healthpromoting behaviors in African American Elders. Rehabilitation Psychology. 2008; 53:85-92.

Pearlin LI, Lieberman MA, Menaghan EG, et al. The stress process. Journal of Health and Social behavior. 1981; 22:337-356. [PubMed: 7320473]

Pratt, LA.; Brody, DJ. Depression in the United States household population. National Center for Health Statistics. 2008. September 2008 http://www.cdc.gov/nchs/data/databriefs/db07.pdf

Ralston PA, Ilich-Ernst J, Wickrama KAS, Harris CM. Reducing cardiovascular disease risk in African Americans. National Center on Health and Health Disparities funded project. $2008 \mathrm{NIH}$ Award, R24MD002807. 3b.

Ratna J, Rifkin SB. Equity, empowerment, and choice: From theory to practice in public health. Journal of Health Psychology. 2007; 12:517-530. [PubMed: 17440001]

Richert J, Reuter T, Wiedemann AU, et al. Differential effects of planning and self-efficacy on fruit and vegetable consumption. Appetite. 2010; 54:611-614. [PubMed: 20227450]

Rimal RN. Perceived risks and self-efficacy as motivators: Understanding individuals' long-term use of health information. Journal of Communication. 2001; 51:633-654.

Seeman M, Seeman TE. Health behavior and personal autonomy: A longitudinal study of the sense of control in illness. Journal of Health and Social behavior. 1983; 24:144-160. [PubMed: 6886369]

Seligman MEP, Csikszentmihalyi M. Positive psychology: An introduction. The American Psychologist. 2000; 55:5-14. [PubMed: 11392865]

Shuey KM, Wilson AE. Cumulative disadvantage and Black-White disparities in life-course health trajectories. Research on Aging. 2008; 30:200-225.

Taylor J, Turner RJ. Perceived discrimination, social stress, and depression in the transition to adulthood: Racial contrasts. Social Psychology Quarterly. 2002; 65:213-225. 
Thompson SC. Will it hurt less if I can control it? A complex answer to a simple question. Psychological Bulletin. 1981; 90:89-101. [PubMed: 7267899]

Warner DF, Hayward MD. Early-life origins of the race gap in men's mortality. Journal of Health and Social behavior. 2006; 47:209-226. [PubMed: 17066773]

Whitbeck LB, Simons RL, Conger RD, et al. The effects of parents' working conditions and family economic hardship on parenting behaviors and children's self-efficacy. Social Psychology Quarterly. 1997; 60:291-303.

Wickrama KAS, Ralston PA, O’Neal CW, et al. Life dissatisfaction and eating behaviors among older African Americans: The protective role of social support. The Journal of Nutrition, Health \& Aging. 2012b; 16:749-753.

Wickrama KAS, Ralston PA, O'Neal CW, et al. Linking life dissatisfaction to health behaviors of older African Americans through psychological competency and vulnerability. Research on Aging. $2012 \mathrm{a}$

Wickrama KAS, Surjadi FF, Lorenz FO, et al. Family economic hardship and progression of poor mental health in middle-aged husbands and wives. Family Relations. 2012c; 61:297-312. [PubMed: 22577243]

Wolinsky FD, Johnson RJ. The use of health services by older adults. The Journals of Gerontology Series B, Psychological Sciences and Social Sciences. 1991; 46:S345-S357.

Woodgate J, Brawlay LR. Self-efficacy for exercise in cardiac rehabilitation: Review and recommendations. Journal of Health Psychology. 2008; 13:366-387. [PubMed: 18420771] 


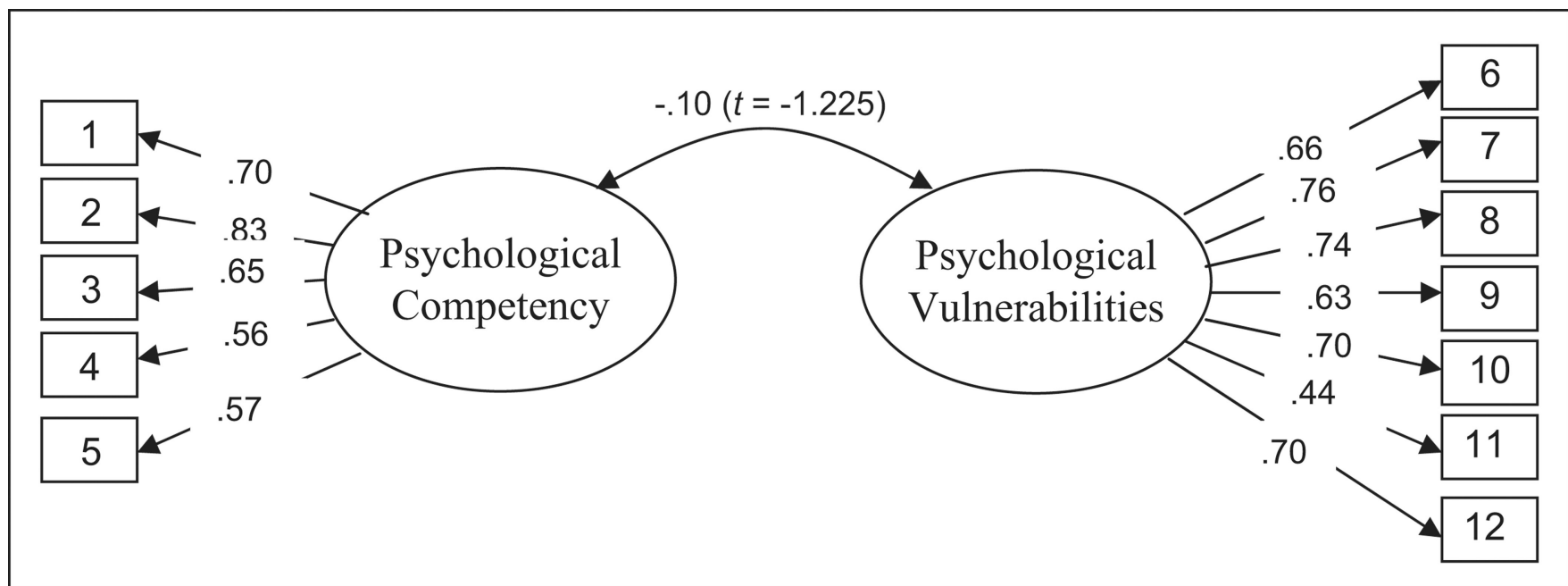

Figure 1. Two distinct factors of psychological competency and vulnerability as indicated from a confirmatory factor analysis of 12 items from the PSS (Cohen et al., 1983)

Source: Adapted from Wickrama et al. (2012b).

Notes: See the text for sample scale items. Model fit indices $\chi^{2} / \mathrm{df}=1.86, \mathrm{CFI}=.94$, RMSEA = .062. CFI: comparative fit index; df: degrees of freedom; PSS: Perceived Stress Scale; RMSEA: root mean square error of approximation. 


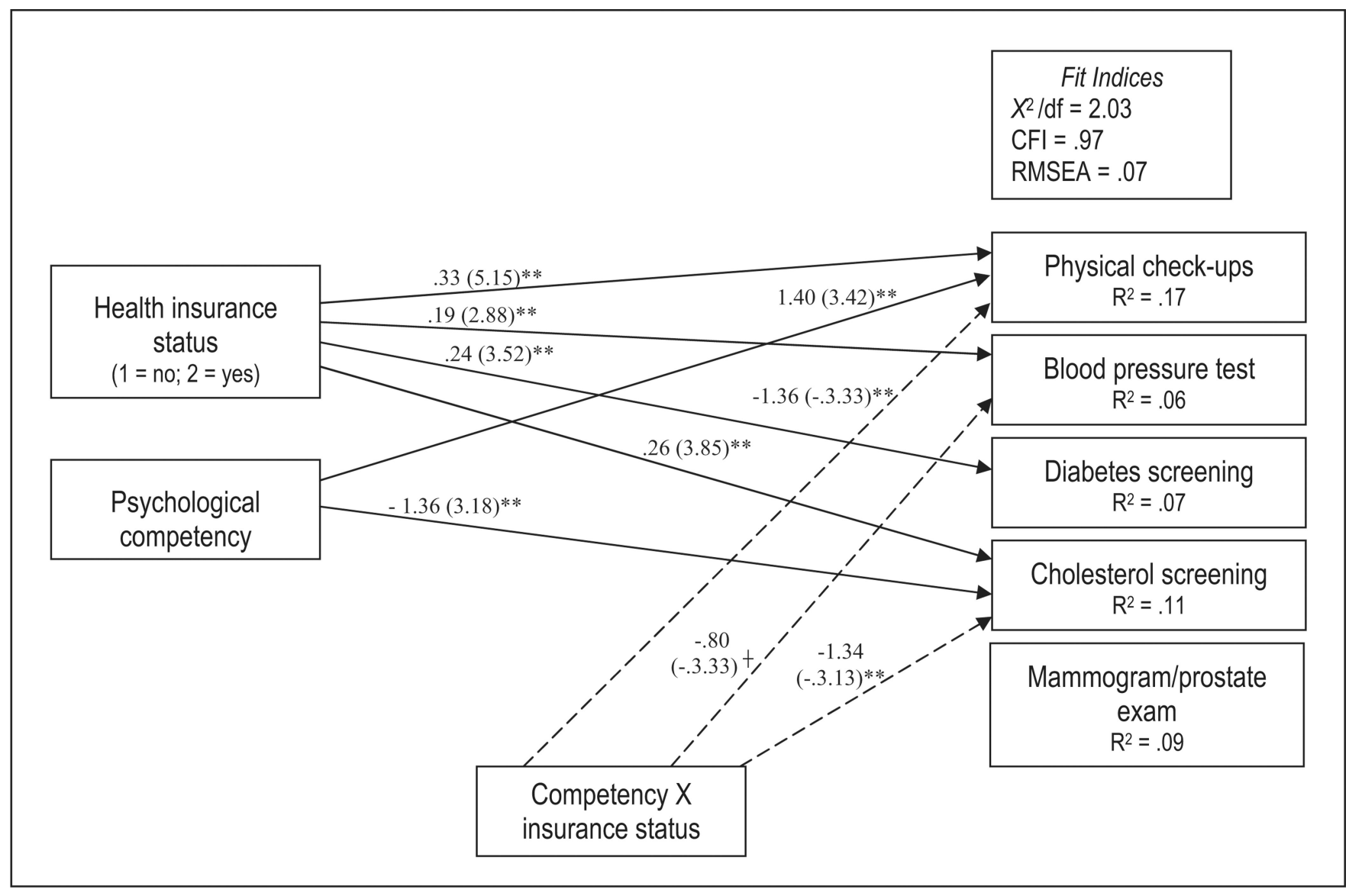

Figure 2. Health insurance, psychological competency, and older African Americans' utilization of five preventive care services

CFI: comparative fit index; df: degrees of freedom; RMSEA: root mean square error of approximation.

Notes: (1) For ease of reader interpretation, only statistically significant paths are shown and standardized coefficients are reported. (2) Age, gender, marital status, education, and health status were included as control variables predicting all preventive care services. The only significant paths were found for gender and health status, indicating that older African American males $(\beta=0.22, p<.01)$ and those in poor health $(\beta=-0.20, p<.01)$ were more likely than females and healthy individuals to have regular gender-specific cancer screenings. (3) Statistically significant interaction paths between psychological competency and health insurance status are shown as broken lines.

${ }^{\dagger} p=.06 ; * p<.05 ; * * p<.01$. 


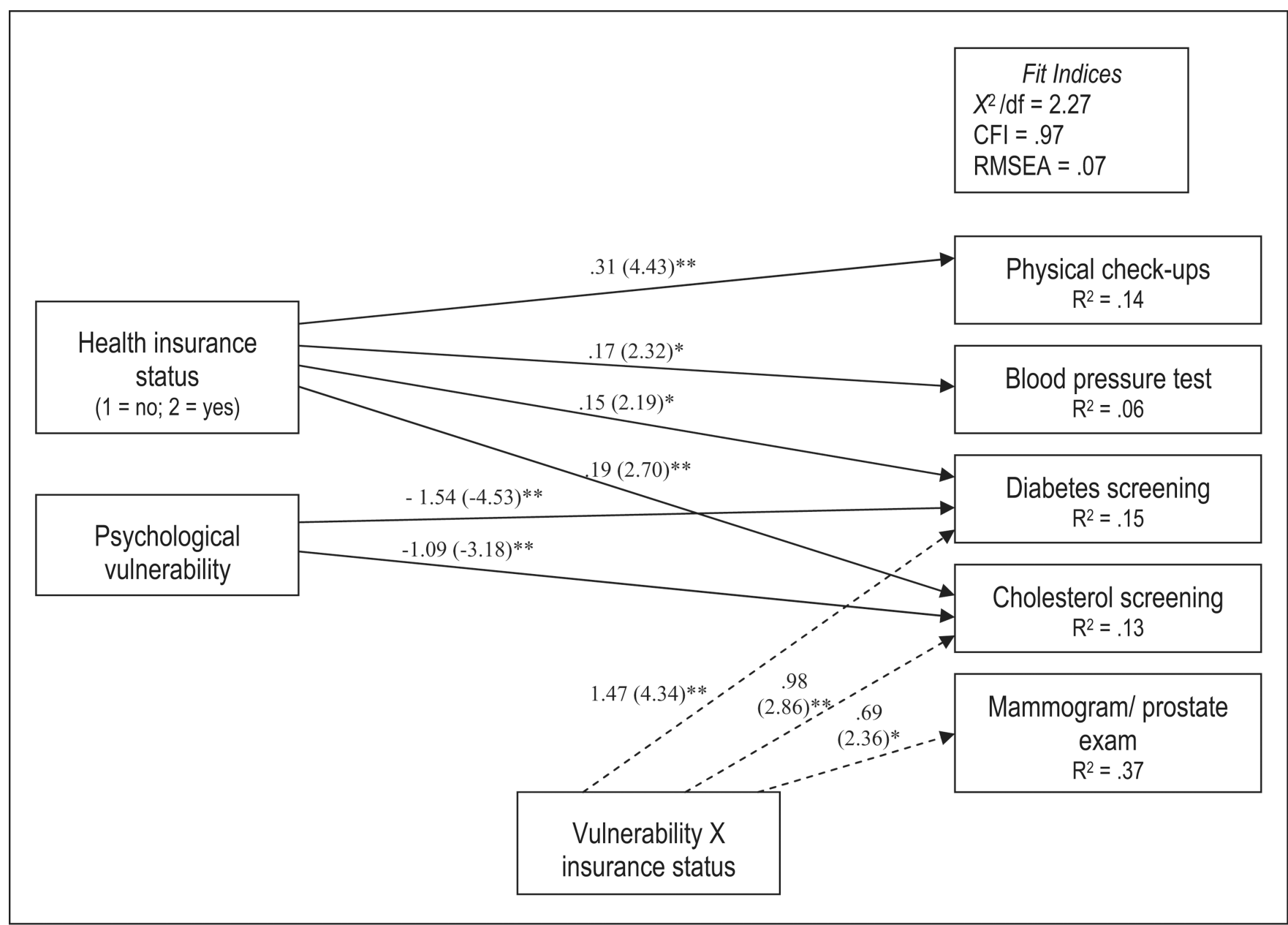

Figure 3. Health insurance, psychological vulnerability, and older African Americans' utilization of five preventive care services

CFI: comparative fit index; df: degrees of freedom; RMSEA: root mean square error of approximation.

Notes: (1) For ease of reader interpretation, only statistically significant paths are shown and standardized coefficients are reported. (2) Age, gender, marital status, education, and health status were included as control variables predicting all preventive care services. The only significant paths were found for gender and health status, indicating that older African American males $(\beta=0.20, p<.01)$ and married individuals $(\beta=0.13, p<.05)$ were more likely than females and healthy individuals to have regular gender-specific cancer screenings. Yet, married individuals were less likely to have a doctor test their blood pressure frequently $(\beta=-0.12, p<.01)$. (3) Statistically significant interaction paths between psychological competency and health insurance status are shown as broken lines. $* p<.05 ; * * p<.01$. 


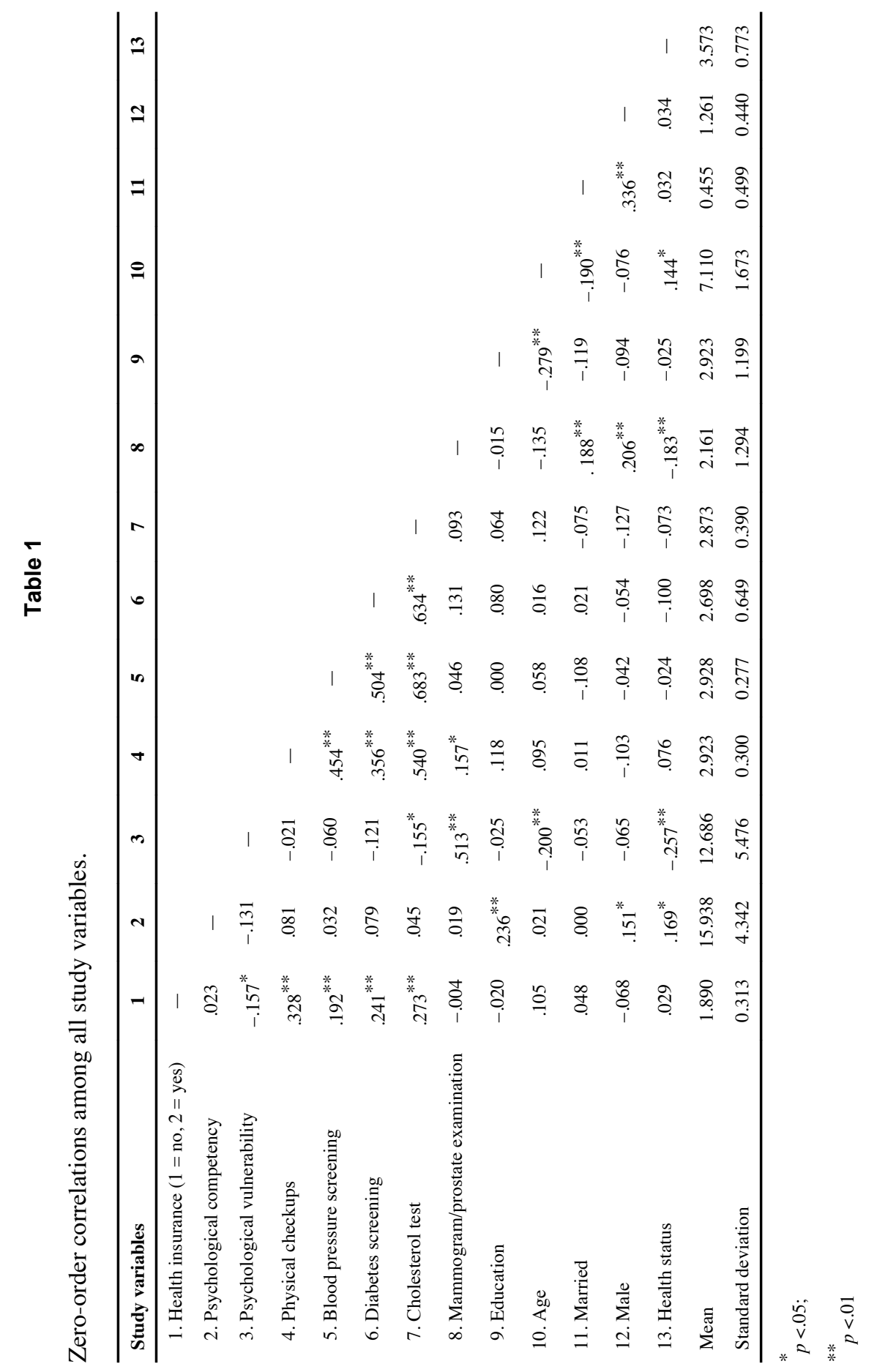

J Health Psychol. Author manuscript; available in PMC 2014 July 01. 